\title{
CIDADES GATEWAY NAS REDES DE PRODUÇÃO GLOBAIS: UM CONCEITO ILUSTRADO PELO SETOR DE PETRÓLEO E GÁS NA AMÉRICA DO SUL E ÁFRICA SUBSAARIANA
}

\author{
Sören Scholvin ${ }^{1}$ \\ Mariane Santos Françoso ${ }^{2}$ \\ Patricia Alencar Silva Mello ${ }^{3}$ \\ Moritz Breul ${ }^{4}$ \\ Celio Hiratuka ${ }^{5}$
}

Resumo: Cidades globais e redes de produção globais (RPG), abordagens analíticas fundamentais na Geografia Econômica, são aspectos definidores da economia global atual. Os conceitos de cidades globais e RPG são explorados no presente artigo, com o argumento de que algumas cidades globais, por integrarem suas esferas de influência em RPG, funcionam como "gateways". Contudo, enquanto o conceito de cidades globais está concentrado nos serviços avançados e na presença de sedes corporativas, o de cidades gateway é marcado por cinco dimensões: logística e transporte, processamento industrial, controle corporativo, prestação de serviços e geração de conhecimento. Apesar do escopo conceitual deste artigo, cada uma das dimensões é também contextualizada a partir de exemplos do setor de petróleo e gás da América do Sul e da África Subsaariana. Essas informações empíricas ilustram a relevância das cinco dimensões apontadas para o desenvolvimento em um contexto de redes.

Palavras-chave: Cidades Gateway; Cidades Globais; Redes de Produção Globais; Indústria de Petróleo e Gás.

\section{GATEWAY CITIES IN GLOBAL PRODUCTION NETWORKS: A CONCEPT ILLUSTRATED BY THE OIL AND GAS SECTOR IN SOUTH AMERICA AND SUB-SAHARAN AFRICA}

Abstract: Global cities and global production networks are defining features of the contemporary global economy. They are also key analytical approaches in Economic Geography. This article brings global cities and global production networks together,

\footnotetext{
${ }^{1}$ Pesquisador no Instituto de Geografia Econômica e Cultural - Universidade de Hanôver scholvin@ wigeo.uni-hannover.de

${ }^{2}$ Doutoranda em Economia na Universidade Estadual de Campinas (UNICAMP). marisfrancoso@gmail.com

${ }^{3}$ Doutoranda na Escola de Administração Pública de São Paulo - Fundação Getúlio Vargas. patricia.mello@gvmail.br

${ }^{4}$ Doutorando no Instituto de Geografia - Universidade de Colônia. moritz.breul@uni-koeln.de

${ }^{5}$ Docente no Instituto de Economia - Universidade Estadual de Campinas (UNICAMP). celiohiratuka@gmail.com

Estudos Geográficos, Rio Claro, 17(1): 91-114, jan./jun. $2019 \quad$ (ISSN 1678-698X) http://www.periodicos.rc.biblioteca.unesp.br/index.php/estgeo
} 
arguing that some global cities serve as "gateways", integrating their spheres of influence into global production networks. Whereas the concept of global cities concentrates on advanced producer services and corporate headquarters, gateway cities are marked by five dimensions: logistics and transport, industrial processing, corporate control, service provision and knowledge generation. Whilst the main purpose of this article is to advance the concept of gateway cities, each of the five dimensions is illustrated by examples from the oil and gas sector in South America and sub-Saharan Africa. This empirical information illustrates the relevance of the five gateway dimensions for development in networks.

Keywords: Gateway Cities; Global Cities; Global Production Networks; Oil and Gas Industry.

\section{INTRODUÇÃO}

A economia global é organizada em redes de produção globais (RPG) e ao longo de cidades globais, incluindo as do Sul Global. Capturando o contexto das cadeias de valor de forma mais ampla, as RPG "incorporam todos os tipos de relações da rede produtiva e englobam todos os conjuntos relevantes de atores" envolvidos em um processo de produção e comercialização (COE, DICKEN e HESS, 2008, p. 272). Podemos afirmar que a abordagem RPG tornou-se uma das mais utilizadas na Geografia Econômica. As cidades globais, por sua vez, são consideradas "pontos de base" do capital global (FRIEDMANN, 1986, p. 69). São "pontos de comando altamente concentrados" de onde os processos econômicos globais são controlados (SASSEN, 2001a, p. 03).

Alguns autores sugerem que as cidades globais integram suas respectivas regiões na economia global em razão de seu papel decisivo nas RPG. Taylor et al. (2002) classificam algumas cidades globais como "centros de comando regionais", afirmando que tais cidades atuam como pontos de articulação entre suas esferas de influência e outras cidades globais. Rossi, Beaverstock e Taylor (2005, 2007) mostram que algumas cidades brasileiras, especialmente o Rio de Janeiro e São Paulo, servem de "centros de serviços" para empresas brasileiras que buscam internacionalizar seus negócios. Sigler (2013) explica de que forma "cidades relacionais" funcionam como intermediárias entre economias globais e regionais. Parnreiter (2010, 2015), estudando os casos da Cidade do México e Hamburgo, mostra que os serviços avançados prestados nessas cidades têm o papel de interligar suas regiões de influência globalmente.

Baseando-se na literatura sobre cidades globais, este artigo amplia a pesquisa sobre a interação dessas com as RPG, identificando cinco dimensões que possibilitam a articulação de processos locais na economia global para além do controle corporativo e dos serviços avançados (as categorias mais analisadas na pesquisa sobre cidades globais, tratadas como características definidoras destas). Dada a função de interligação que algumas cidades globais desempenham nas RPG, optou-se neste artigo por nomeá-las como "cidades gateway". As cinco dimensões que caracterizam as cidades gateway são: logística e transporte, processamento industrial, controle corporativo, prestação de serviços e geração de conhecimento. Essas dimensões não são necessariamente alcançadas por todas as cidades gateway. Como será mostrado nesse artigo, as dimensões são cruciais para

Estudos Geográficos, Rio Claro, 17(1): 91-114, jan./jun. 2019 (ISSN 1678-698X) http://www.periodicos.rc.biblioteca.unesp.br/index.php/estgeo 
o desenvolvimento em um contexto de redes e a abordagem aqui desenvolvida permite um melhor entendimento do papel das cidades como centros de atividade econômica, especialmente em relação ao desenvolvimento gerado pela integração destas em RPG.

Este artigo está estruturado da seguinte forma: primeiramente será discutido em linhas gerais o papel desempenhado pelas cidades globais nas RPG, enfatizando as cinco dimensões de cidades gateway e discutindo o desenvolvimento em um contexto de redes. Na sequência, são contextualizadas essas cinco dimensões em um debate mais amplo sobre as cidades globais, as RPG e, relacionado a isso, o desenvolvimento econômico. Para cada dimensão apontada são fornecidos exemplos do setor de petróleo e gás na América do Sul e na África Subsaariana. Estes exemplos empíricos (que servem para ilustrar as dimensões gateway) são baseados em dados obtidos no site "A Barrel Full", nos sites de empresas do setor e em entrevistas realizadas pelos autores em 2016 e 2017.

\section{AS CIDADES GLOBAIS NAS RPG}

A ideia de que as cidades são decisivas para a organização da produção e do comércio global não é nova. Knox observou no final dos anos 1990 que algumas cidades são "pontos nodais em cadeias de commodities globais" (1997, p. 17). Rabach e Kim afirmaram alguns anos antes que "sem a função de integração e coordenação desempenhada para os serviços, as cadeias de valor globais seriam inviáveis no atual ambiente econômico altamente competitivo" (1994, p. 123), o que implica que as RPG e as cidades globais, principais fornecedoras de serviços, têm de ser pensadas em conjunto.

A abordagem RPG explora a criação, o aprimoramento e a captura de valor nas redes de produção, além do enraizamento local dessas redes e da distribuição de poder entre os diferentes atores envolvidos (HENDERSON et al., 2002). Esse processo é estabelecido por meio dos chamados "acoplamentos estratégicos", ou seja, por intermédio da incorporação de ativos locais nas RPG (COE et al., 2004). O acoplamento estratégico ocorre através de investimentos locais brownfield e greenfield por empresas não-locais (tanto empresas domésticas como estrangeiras; geralmente, mas não necessariamente, empresas líderes das respectivas RPG), além de várias formas de cooperação entre empresas locais e não-locais e conexões extra-locais estabelecidas dentro dos territórios. Esse movimento é explicado tanto pelo interesse na utilização de recursos locais humanos e nãohumanos quanto pela necessidade de acesso a mercados locais de bens e serviços (COE e YEUNG, 2015; DICKEN, 2015).

A partir dessas considerações surgem as seguintes questões: qual papel as cidades globais desempenham nas RPG? De acordo com Friedmann e Wolff, as cidades globais ocupam o mais alto nível hierárquico na economia global. Elas estão "estreitamente ligadas umas às outras por meio do processo de tomada de decisão e das finanças, [constituindo] um sistema mundial de controle sobre a produção e a expansão do mercado" (1982, p. 310). Essas cidades "servem como centros bancários e financeiros, centros administrativos [e] centros de controle ideológico [...] Sem elas, o sistema mundial de relações econômicas seria impensável" (1982, p. 311-312). Assim, elas exercem um papel de governança da economia global, o que fundamentalmente as define, razão pela qual a categoria inclui lugares tão diferentes como o Cairo, Tóquio e Zurique.

Estudos Geográficos, Rio Claro, 17(1): 91-114, jan./jun. 2019 (ISSN 1678-698X) http://www.periodicos.rc.biblioteca.unesp.br/index.php/estgeo 
As pesquisas que se desenvolvem a partir da abordagem de Friedmann e Wolff concentram-se nas relações entre matriz e subsidiária de empresas transnacionais (ALDERSON e BECKFIELD, 2004, 2012; WALL e VAN DER KNAAP, 2012). Alguns pesquisadores, em particular os vinculados ao grupo Globalização e Cidades Globais, deslocam o foco analítico para os chamados serviços avançados. Segundo Sassen (2001a, 2001b), os serviços avançados - de bancos/finanças, contabilidade, direito e publicidade - são essenciais para as empresas transnacionais devido à crescente complexidade da produção e do comércio globalizados. A autora considera que as cidades globais possuem o ambiente de negócios necessário para a geração desses serviços, pois elas constituem uma malha de informações que não podem ser replicadas por meio de telecomunicação. Ao concentrar e fornecer serviços avançados, as cidades globais tornam-se, como já mencionado anteriormente, "pontos de comando altamente concentrados" de onde os processos econômicos globais são controlados (SASSEN, 2001a, p. 03).

Contudo, interessam à presente pesquisa alguns pontos específicos do estudo sobre cidades globais, especialmente aqueles que enfatizam o papel destas como gateways. Esse papel já vem sendo abordado por diversos autores, embora nem sempre com a mesma nomenclatura:

- Grant e Nijman (2002) afirmam que Accra e Mumbai são cidades gateway, focando no desenvolvimento de diferentes distritos de negócios centrais: ambas as cidades têm distritos de negócios locais, nacionais e globais.

- Parnreiter, Haferburg e Oßenbrügge (2013) aplicam este conceito à Cidade do México e Joanesburgo, sugerindo que as empresas que abrem escritórios nos distritos de negócios usam essas cidades como gateways para suas regiões.

- Short et al. (2000) afirmam que todas as cidades são de alguma forma gateways por globalizar suas esferas de influência em âmbito cultural, econômico e político.

- Taylor et al. (2002) rotulam algumas cidades globais como "centros de comando regionais".

- Baseando-se em uma análise de serviços avançados, Rossi, Beaverstock e Taylor $(2005,2007)$ mostram como as "cidades de serviços" servem de trampolins para as empresas brasileiras que buscam internacionalizar suas atividades.

- Sigler (2013) chama a Cidade do Panamá, Doha e Dubai de "cidades relacionais" por conta do excelente ambiente de negócios que elas oferecem. Elas conectam as escalas globais e regionais.

- Parnreiter $(2010,2015)$ mostra como os prestadores de serviços avançados de Hamburgo ajudam seus clientes a tornar-se ativos globalmente e como as empresas da Cidade do México interligam outros lugares do país globalmente.

Entretanto, além dessa literatura, antes do início da pesquisa sobre cidades globais, Burghardt já definia cidades gateway como "uma entrada em (e necessariamente uma saída de) alguma área" (1971, p. 269), sugerindo que as cidades gateway serviam como canais de transmissão entre suas regiões de influência e o mundo exterior. A função de interligação das cidades gateway vem acompanhada do controle dos processos econômicos e de uma hierarquia territorial clara: "a cidade [gateway] está no comando das conexões entre sua região e o mundo exterior" (BURGHARDT, 1971, p. 269).

Aparentemente, a principal característica das cidades gateway é o fato destas consistirem em um ambiente de negócios favorável. Burghardt referiu-se a exemplos da América do Norte e do Sudeste da Europa desde o início do século XIX Estudos Geográficos, Rio Claro, 17(1): 91-114, jan./jun. 2019 (ISSN 1678-698X) http://www.periodicos.rc.biblioteca.unesp.br/index.php/estgeo 
até meados do século XX. Ele apontou que as cidades gateway apresentam desempenho excepcional principalmente em termos de serviços empresariais, tais como bancos, empresas de crédito, agências imobiliárias, hotéis e restaurantes sendo os dois últimos considerados condição básica para empresários que para lá viajam. Burghardt também enfatizou a infraestrutura de transporte - cidades gateway possuem grandes portos e/ou são lugares onde diferentes rotas de transporte se encontram -, além do comércio. Considerando o trabalho de Burghardt, incluímos serviços não-avançados também nessa análise. Quando se trata de integrar locais periféricos do Sul Global às RPG, não só os serviços altamente sofisticados são importantes. Questões como manutenção e reparação de equipamentos e treinamento, por exemplo, também são relevantes (SCHOLVIN, 2017).

Contrariamente à ideia de Burghardt, as publicações mais recentes, discutidas nos parágrafos anteriores, concentram-se em controle corporativo e serviços avançados para caracterizar as cidades gateway. Nesse contexto, as cidades analisadas por Burghardt não seriam consideradas cidades globais. Todavia, algumas das cidades globais são gateways. Como já enfatizado, diferentes conceitos de cidades gateway têm sido discutidos com sucesso no âmbito das pesquisas sobre cidades globais. A diferença entre a perspectiva de cidades gateway e de cidades global é que a última aborda hierarquias intrafirma e ligações entre fornecedores de serviços avançados. Essas ligações são estabelecidas entre cidades globais e são essenciais para o entendimento da governança dos processos econômicos. Enquanto isso, a perspectiva gateway captura as ligações estabelecidas tanto global como regionalmente. Essa perspectiva está menos preocupada com a governança, desviando o foco para a divisão de funções, o que auxilia o entendimento do desenvolvimento em redes. Comparado ao conceito de cidades globais, o conceito de cidades gateway permite uma compreensão mais ampla das cidades como intermediárias nos processos econômicos.

Avançar no conceito de cidades gateway é especialmente importante, pois as conexões estabelecidas entre estas cidades e suas regiões de influência são raramente exploradas na literatura de cidades globais, embora se reconheça cada vez mais que os fluxos globais são apenas um aspecto da conectividade das cidades (SURBORG, 2011; SMITH, 2014). Isso pode ser explicado pelo fato de que o trabalho de Sassen - ainda a principal referência na pesquisa sobre cidades globais - mantém-se alheio à regionalização das cidades globais. Sassen alega que "ao contrário de outros tipos de serviços, [os serviços avançados] dependem muito pouco da proximidade dos consumidores" (2001a, p. 11). Se isso fosse verdade, não haveria necessidade de cidades gateway, pois RPG na África Subsaariana seriam mantidas funcionais por prestadores de serviços sediados em Londres e Nova York; empresas brasileiras que buscam internacionalizar seus negócios fariam isso com a ajuda de bancos e consultores de qualquer cidade do mundo, não necessariamente de uma cidade no Brasil.

Essa configuração, contudo, não parece convincente. O que o presente artigo argumenta é que a função gateway que algumas cidades globais desempenham baseia-se em um conjunto de ativos específicos de cada região. Concentrar-se apenas em serviços avançados (ou, ainda pior, nas sedes de empresas) leva a uma análise incompleta e viesada. Esses aspectos são importantes, mas representam apenas duas dimensões das cidades gateway. A função de interligação que elas assumem nas RPG é muito mais ampla:

Estudos Geográficos, Rio Claro, 17(1): 91-114, jan./jun. $2019 \quad$ (ISSN 1678-698X) http://www.periodicos.rc.biblioteca.unesp.br/index.php/estgeo 
Primeiro, diferentes pesquisadores mostraram que algumas cidades globais são centros de transporte (GRUBESIC e MATISZIW, 2012; HESSE, 2010; JACOBS, DUCRUET e DE LANGEN, 2010). As cidades relacionais de Sigler (2013) desempenham um papel fundamental na rede global de fluxos porque são, em primeiro lugar, centros de logística, armazenamento e comércio. Bancos centrais e bolsas de valores não constituem elementos definidores dessas cidades. Além disso, como visto, Burghardt (1971) enfatizou a importância do comércio e da infraestrutura de transporte.

Segundo, cidades globais do Sul Global também acomodam grandes indústrias, como demonstra Joanesburgo, o coração industrial não só da África do Sul, mas de toda a África Subsaariana (AKINBOADE e LALTHAPERSAD-PILLAY, 2009; TRIBE, 2002). A fabricação de automóveis em São Paulo também exemplifica a relevância das cidades globais no Sul Global como espaços de produção industrial conectado além das fronteiras (HUMPHREY, 2003; RAMOS SCHIFFER, 2002).

Terceiro, enquanto as quatro dimensões que já foram mencionadas controle corporativo e prestação de serviços, baseados em trabalhos já realizados no âmbito da pesquisa em cidades globais, assim como logística e transporte e processamento industrial - derivam da literatura de cidades globais, inúmeras outras pesquisas mostram que a criatividade e a inovação caracterizam (algumas) áreas urbanas (FLORIDA, 2005; HOSPERS, 2003; YUSUF e NABESHIMA, 2005). Dessa forma, a geração de conhecimento é considerada uma quinta dimensão das cidades gateway.

Adicionalmente, as cidades gateway geram oportunidades de desenvolvimento econômico através do acoplamento estratégico. Elas são locais onde as RPG estão conectadas ao território, onde grandes empresas estrangeiras e nacionais interagem com parceiros locais para a realização de atividades cruciais para as RPG. Ideias semelhantes foram discutidas no World Development Report do ano 2009, que introduziu o termo "área líder". Uma área líder é um local relativamente avançado e de rápido crescimento - as regiões metropolitanas de São Paulo e do Rio de Janeiro, por exemplo. O Banco Mundial sugere que os países em desenvolvimento se liguem a áreas líderes, permitindo o livre fluxo de capital, bens e pessoas, a fim de que estes se beneficiem de impulsos para o desenvolvimento econômico. Cidades gateway são áreas líderes.

De acordo com o World Development Report, áreas líderes são locais de densidade econômica, implicando que muitas empresas estão ali concentradas, beneficiando-se de economias de escala e oportunidades de colaboração. Contudo, a densidade não funciona em lugares individuais, isolados de atividades econômicas em outros lugares. É um processo interligado ou, em outras palavras, se trata do desenvolvimento em redes. A densidade e as vantagens de localização resultantes nas redes são capturadas pelas cinco dimensões de gateway apresentadas neste artigo. Assim, a abordagem desenvolvida aqui não apenas amplia a pesquisa em cidades globais, mas também oferece uma maneira de entender melhor 0 desenvolvimento em redes, para compreender por que e como lugares específicos se beneficiam de sua integração em atividades econômicas globais.

\section{FUNÇÕES DAS CIDADES GATEWAY}

As cinco dimensões desenvolvidas acima definem as cidades gateway. Elas explicam a função de interligação dessas cidades nos processos econômicos. As

Estudos Geográficos, Rio Claro, 17(1): 91-114, jan./jun. 2019 (ISSN 1678-698X) http://www.periodicos.rc.biblioteca.unesp.br/index.php/estgeo 
cinco dimensões gateway não são necessariamente aditivas. Elas podem surgir isoladamente ou em diferentes combinações, resultando em tipos distintos de gateways. Além disso, as cinco dimensões constituem uma hierarquia de sofisticação, em que os locais mais voltados ao controle corporativo, prestação de serviços e/ou de geração de conhecimento funcionam como gateways muito diferentes dos que apresentam apenas as dimensões de logística e transporte ou de processamento industrial. Ainda assim, as funções de gateway menos sofisticadas são cruciais para manutenção das RPG.

As seções empíricas deste artigo são baseadas em uma abordagem de métodos mista. Como já mencionado, foram usados dados obtidos no site "A Barrel Full", nos sites de empresas do setor e em entrevistas realizadas pelos autores em 2016 e 2017. A base "A Barrel Full" fornece dados sobre os diferentes poços de petróleo e gás existentes no mundo, com informações relativas à localização destes (país, cidade, bacia), empresas operadoras e prestadoras de serviços atuantes. Após a coleta inicial desses dados, foi realizada uma busca nos sites das empresas citadas (operadoras e prestadoras de serviço), a fim de identificar em quais cidades tais empresas estão localizadas.

As entrevistas foram realizadas em cidades gateway selecionadas e a periferia delas (Buenos Aires e Neuquén na Argentina, Cidade do Cabo e Durban na África do Sul, Guarujá, Rio de Janeiro e São Paulo no Brasil). Foram realizadas a partir de um roteiro de oito questões, cobrindo aspectos relativos às vantagens e desvantagens de localização, organização intra-firma e relações entre empresas operadoras, prestadoras de serviços e fornecedores. As questões derivam do entendimento da dinâmica das cidades gateway apresentada neste artigo. Os entrevistados foram identificados através de seus perfis pessoais no Linkedin. Estes, por sua vez, indicaram outras pessoas do setor para serem entrevistadas, o que foi particularmente importante para o estabelecimento de contato com pequenos prestadores de serviços. A fim de analisar as entrevistas, as informações obtidas foram estruturadas em categorias pré-definidas, a partir das dimensões gateway.

O foco do trabalho no setor de petróleo e gás - não afirmando que as conclusões desenvolvidas podem ser válidas para outros setores - tem duas razões. Primeiramente, informações básicas sobre o setor, como propriedade, prestação de serviços e unidades de processamento, estão disponíveis online. Também houve certa facilidade em acessar empresas líderes e diversas pequenas empresas para a realização de entrevistas, a fim de obter informações sobre estratégias de localização e cooperação com outras empresas. Segundo, o setor de petróleo e gás é adequado para mostrar como os diferentes segmentos das RPG estão geograficamente dispersos pelo globo, como eles tornam cidades em gateways a partir das já mencionadas cinco dimensões e como isso influencia no desenvolvimento em um contexto de redes.

\section{LOGÍSTICA E TRANSPORTE}

O fato de que alguns locais interligam a periferia ao sistema global não é novidade. Durante a era colonial existiram diversos pequenos gateways no Sul Global. A conquista europeia da África, das Américas e de grande parte da Ásia começou em baías que ofereciam proteção contra correntes oceânicas e tempestades. As colônias construíram então linhas ferroviárias a partir destes portos, que também serviram de sedes administrativas e armazéns para exportar minérios e produtos agrícolas e exercer controle territorial.

Estudos Geográficos, Rio Claro, 17(1): 91-114, jan./jun. 2019 (ISSN 1678-698X) http://www.periodicos.rc.biblioteca.unesp.br/index.php/estgeo 
Hoje, os processos de produção funcionalmente fragmentados, que são muitas vezes just in time, tornam a logística e o transporte essenciais para 0 funcionamento das RPG. Os serviços de logística não só permitem fluxos, mas também são decisivos para vantagens competitivas por mitigar o custo da distância. Os lugares que não oferecem nenhuma estrutura adequada de logística e de transporte correm o risco de ser excluídos dos processos econômicos globais, como exemplifica um estudo da indústria eletrônica no sudeste da Ásia de Bowen e Leinbach (2006).

O papel decisivo do transporte é reconhecido nas pesquisas sobre RPG. Robinson (2002), por exemplo, aponta que os portos são componentes importantes das RPG. Para o autor, as autoridades portuárias devem reconhecer o seu papel central na criação de valor e adaptar as suas estratégias nesse sentido. Wang e Cheng (2010) mostram que a relevância dos hubs portuários vai além da função meramente logística. Empresas de logística não só organizam o transporte de mercadorias a partir de hubs, mas também tornam as cadeias de suprimento mais eficientes, diminuindo os custos. O ponto chave, que Wang e Cheng exemplificam com o caso Hong Kong, é que os hubs de transporte em RPG possuem componentes logísticos não-físicos que agregam valor ao comércio através do melhor gerenciamento da cadeia de suprimentos.

Para ilustrar essa função, entrevistas foram realizadas pelos autores deste artigo, a fim de conhecer melhor o papel das cidades de Buenos Aires e Durban. Nessas entrevistas, representantes de grandes empresas internacionais de petróleo e gás apontaram que os seus respectivos centros administrativos e de logística na Argentina estão localizados em Buenos Aires porque não apenas a cidade possui o maior porto do país, mas também oferece uma ampla gama de insumos a preços acessíveis, em comparação a outras cidades argentinas. Como a maioria das empresas envolvidas no setor de petróleo e gás argentino são ativas em várias partes do país, Buenos Aires é um hub para o transporte aéreo de equipamentos e pessoas entre diferentes áreas periféricas do país 6 .

Durban abriga o maior porto da África do Sul e as maiores refinarias do país, com capacidade de 135 mil barris por dia, representando $60 \%$ da capacidade total de refino. Os insumos para essas refinarias são totalmente importados. Durban é conectada por um gasoduto à província de Gauteng, núcleo econômico da África do Sul, onde a grande maioria do petróleo refinado em Durban é consumido. $O$ fato de Durban ser um hub para transporte marítimo e terrestre - e também para o refino de petróleo - abre oportunidades para empresas locais estabelecerem parcerias com investidores estrangeiros. Um entrevistado de uma das maiores companhias de petróleo e gás, que opera uma das refinarias de Durban, revelou que a decisão da companhia por terceirizar o transporte ocorrera há tempos, em razão deste não constituir a principal atividade da empresa e por haver provedores de logística locais suficientemente capazes?

Essas oportunidades para as empresas locais são reforçadas pela legislação de conteúdo local, em razão do empoderamento econômico negro (black economic empowerment, BEE), que é um programa de ação afirmativa lançado pelo governo sul-africano para corrigir as desigualdades resultantes da era do apartheid. A

\footnotetext{
${ }^{6}$ Entrevista presencial realizada com um gerente de uma grande companhia upstream, Buenos Aires, 27 April 2017; entrevista presencial realizada com um executivo de uma transnacional fornecedora de serviços upstream, Buenos Aires, 4 December 2017.

${ }^{7}$ Entrevista presencial realizada com o gerente administrativo local de uma empresa transnacional de petróleo e gás, Durban, 13 Julho 2016.

Estudos Geográficos, Rio Claro, 17(1): 91-114, jan./jun. 2019 (ISSN 1678-698X) http://www.periodicos.rc.biblioteca.unesp.br/index.php/estgeo
} 
parceria com empresas de propriedade não-branca aumenta a classificação BEE de uma empresa, o que lhes dá melhores chances de ganhar licitações para contratos com autoridades públicas e empresas semi-estatais. Como nem todos os potenciais parceiros locais possuem as capacitações necessárias, a empresa do entrevistado está envolvida em aprimoramento de potenciais parceiros, transferindo capacitações-chave para eles.

Outro entrevistado, que trabalha para a instituição de Comércio e Investimento de KwaZulu-Natal, a província onde fica Durban, falou sobre a atração de investidores estrangeiros, que ele coloca em contato com potenciais parceiros locais. Este entrevistado afirmou que havia muito a ser feito para qualificar a mão de obra local em termos de processamento e produção, destacando que alguns insumos essenciais para o setor de petróleo e gás "não podiam ser produzidos na África do Sul naquele momento" e que as empresas estrangeiras deveriam "orientar as locais" de modo que as empresas domésticas, em um momento posterior, sejam capazes de produzir mais insumos ${ }^{8}$. Esta orientação, a transferência de competências de empresas estabelecidas para emergentes, só é possível porque Durban é uma cidade gateway que expõe sua região a empresas transnacionais que procuram acesso ao mercado sul-africano.

\section{PROCESSAMENTO INDUSTRIAL}

Sigler (2013) aponta que as cidades relacionais são diferentes das vilas da era colonial, que ligavam suas esferas de influência às potências coloniais europeias. A mudança mais aparente é devida à industrialização. As cidades gateway não são meras plataformas logísticas. Conforme mencionado, elas concentram indústrias que processam matérias-primas e/ou produtos semimanufaturados. Isso porque, sendo polos industriais, algumas cidades globais no Sul Global assumem um papel de gateway duplo: processam insumos de suas regiões - os produtos acabados são vendidos em todo o mundo - e abrigam empresas estrangeiras que produzem para mercados regionais (DRAPER e SCHOLVIN, 2012).

$\mathrm{Na}$ pesquisa sobre cidades globais, o processamento industrial raramente é discutido pelo simples fato de que as cidades globais no Norte Global são desindustrializadas. No entanto, refinarias de petróleo ilustram como certos locais, incluindo cidades globais no Sul Global, interligam suas periferias globalmente por meio do processamento industrial. Devido às economias de escala, refinarias cada vez maiores estão concentradas em relativamente poucos lugares. Existem cerca de 650 refinarias em todo o mundo. O deslocamento dos mercados consumidores e a tendência das refinarias de se localizarem próximas a eles explicam o crescimento da capacidade no Sul Global, especialmente no Extremo Oriente (BRIDGE e LE BILLON, 2013).

Em outras palavras, a capacidade de refino não é necessariamente construída onde o petróleo é extraído: Angola, Congo-Brazzaville, Gabão e Nigéria têm os maiores volumes de produção de petróleo na África Subsaariana, mas o refino ocorre em grande parte em outros países. A África do Sul - com quase nenhuma produção nacional de petróleo bruto - responde por metade da produção de petróleo refinado na região. A situação parece ser diferente na América do Sul: a

\footnotetext{
${ }^{8}$ Entrevista presencial realizada com o diretor de promoção de Comércio e Investimento KwaZulu-Natal, Durban, 13 Julho 2016.

Estudos Geográficos, Rio Claro, 17(1): 91-114, jan./jun. $2019 \quad$ (ISSN 1678-698X) http://www.periodicos.rc.biblioteca.unesp.br/index.php/estgeo
} 
Argentina e o Brasil não apenas extraem, mas também processam o recurso. Este padrão se aplica também, pelo menos em certa medida, à Colômbia, ao Equador e à Venezuela (AGÊNCIA INTERNACIONAL DE ENERGIA, 2016).

Os mapas 1 e 2 ilustram esse exemplo no nível urbano. Na África Subsaariana, várias refinarias estão localizadas perto de grandes áreas metropolitanas - Sasolburg (80 quilômetros de Joanesburgo), por exemplo - ou em portos importantes como Durban, Mombasa e Tema. Em relação ao petróleo processado, o mapa sul-americano revela que essa atividade concentra-se nas áreas metropolitanas, sendo que $60 \%$ da capacidade de refino da Argentina está na Grande Buenos Aires. A região metropolitana de Lima atinge uma proporção semelhante da capacidade de refino do Peru. No Brasil, que é o principal produtor de petróleo refinado da América do Sul, São Paulo e as cidades vizinhas representam $43 \%$ da capacidade nacional, enquanto apenas $13 \%$ da capacidade de refino está instalada no Rio de Janeiro e seus arredores, que historicamente dominaram o setor nas etapas upstream ${ }^{9}$.

Ao passo que as cidades mencionadas apareçam como gateways para os mercados locais, processando petróleo cru que é importado ou vem de áreas distantes dentro do próprio país, o caso da Venezuela é diferente: $92 \%$ da capacidade de refino está localizada perto dos depósitos do país - Puerto la Cruz e Punta Cardón - e não em Caracas ou nas proximidades. Isso não é surpreendente, dado que o setor petrolífero venezuelano sempre foi orientado à exportação, enquanto os setores downstream argentino, brasileiro e peruano abastecem principalmente os respectivos mercados domésticos. Situação similar ocorre na comparação entre regiões metropolitanas e portuárias da África Subsaariana, onde as importações de petróleo cru têm um papel muito mais importante, considerando que muitos países com grande capacidade de refino não extraem muito petróleo.

\footnotetext{
${ }^{9}$ A indústria de petróleo e gás é comumente dividida em três setores: downstream, midstream e upstream. O setor upstream inclui a procura por poços de petróleo e gás, a perfuração e a operação desses poços. O midstream envolve as atividades de transporte, estocagem e venda do petróleo cru e de produtos refinados. O downstream compreende o refino e processamento do petróleo cru e do gás, além das atividades de marketing e distribuição dos produtos derivados.

Estudos Geográficos, Rio Claro, 17(1): 91-114, jan./jun. 2019 (ISSN 1678-698X) http://www.periodicos.rc.biblioteca.unesp.br/index.php/estgeo
} 
Cidades Gateway...

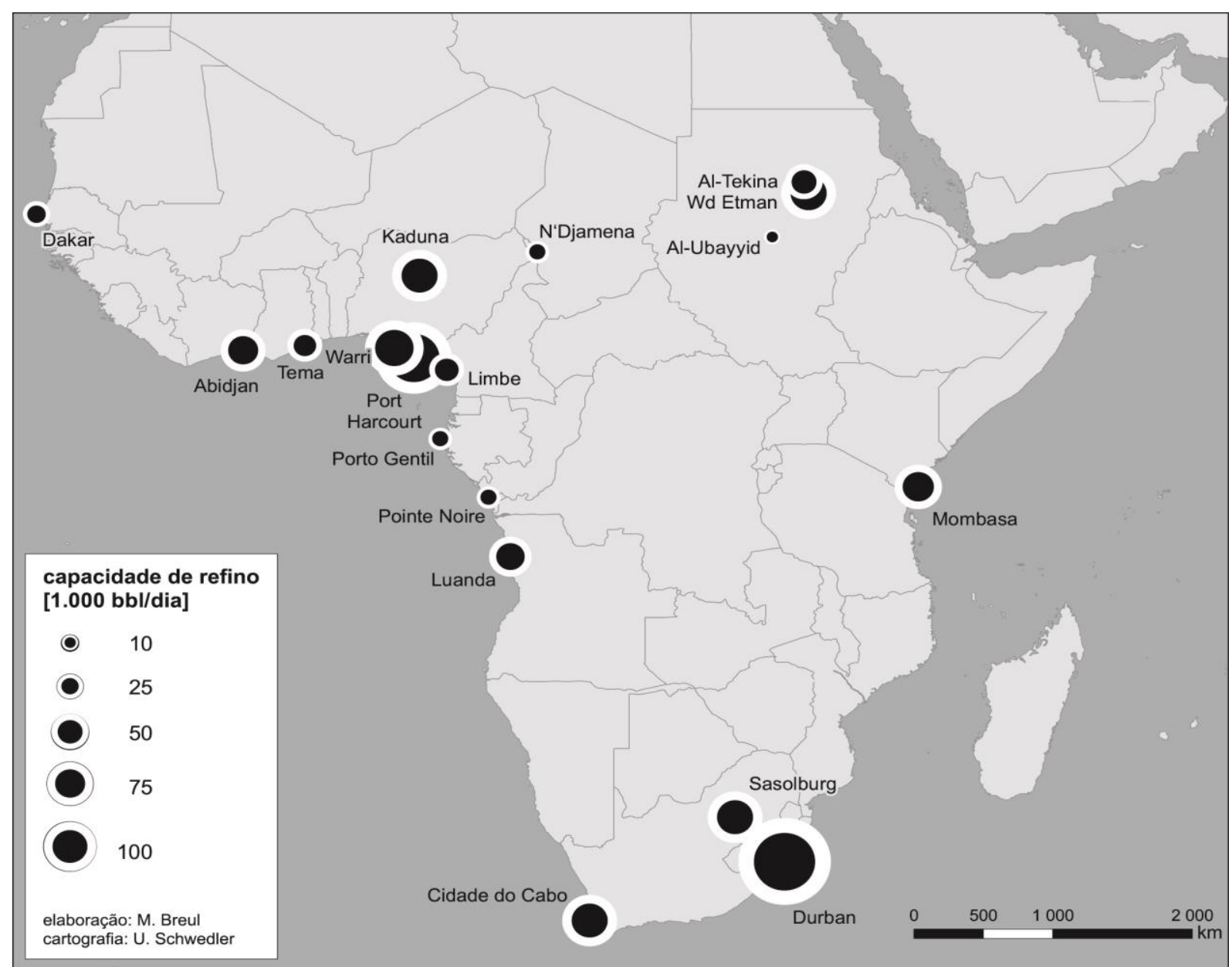

Mapa 1 - Refinarias de petróleo na África Subsaariana.

Fonte: A Barrel Full, 2016a.

Estudos Geográficos, Rio Claro, 17(1): 91-114, jan./jun. 2019 (ISSN 1678-698X) http://www.periodicos.rc.biblioteca.unesp.br/index.php/estgeo 


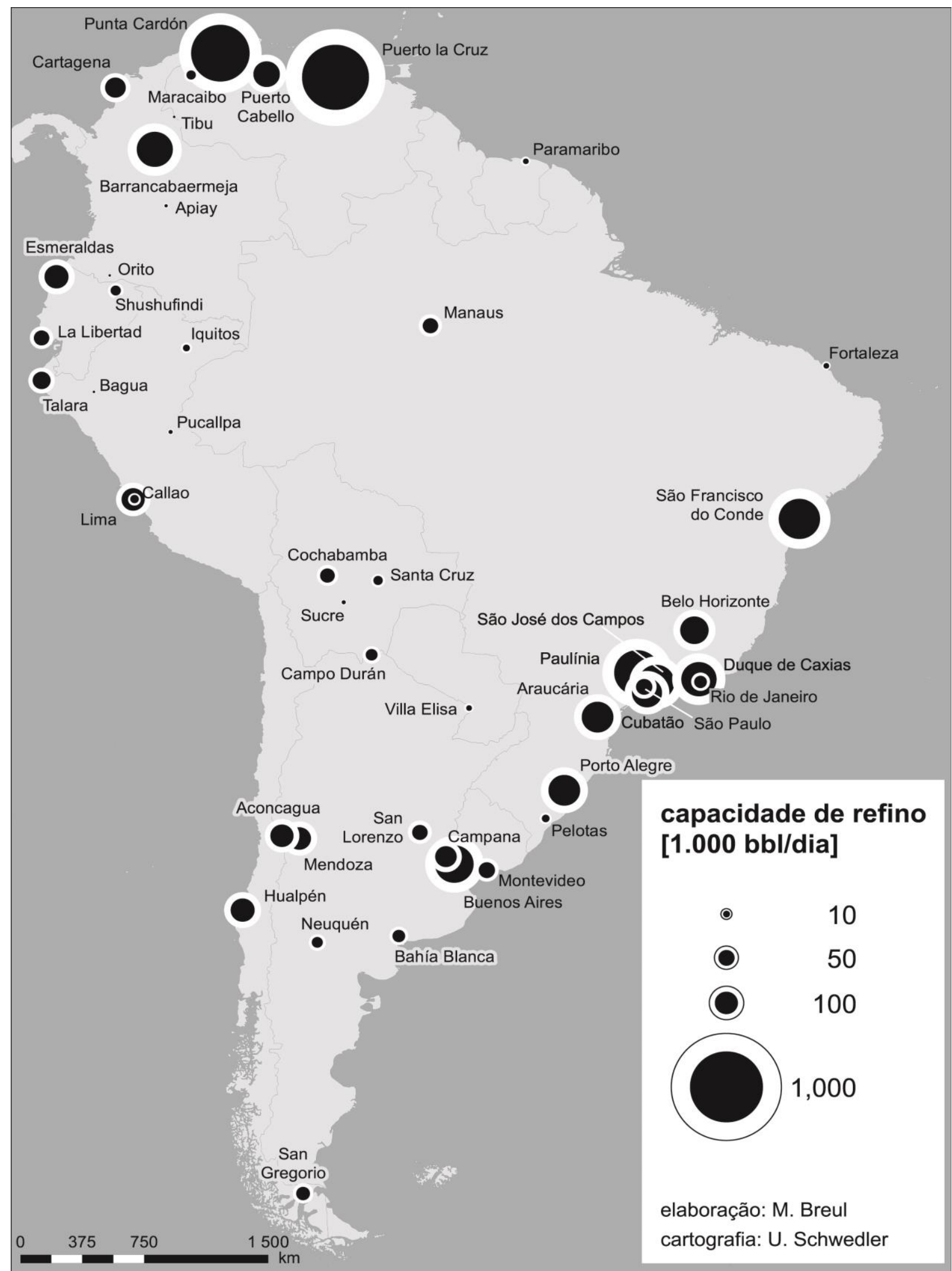

Mapa 2 - Refinarias de petróleo na América do Sul.

Fonte: A Barrel Full, 2016a.

O que esse quadro geral mostra é que algumas cidades globais são importantes locais de processamento industrial, os quais, é plausível concluir, abastecem suas regiões, sendo assim gateways. Esses mercados podem ser Estudos Geográficos, Rio Claro, 17(1): 91-114, jan./jun. 2019 (ISSN 1678-698X) http://www.periodicos.rc.biblioteca.unesp.br/index.php/estgeo 
delimitados pelas fronteiras nacionais, como na América do Sul, ou transcendê-las. As já mencionadas refinarias em Durban, por exemplo, abastecem Botswana e Moçambique. Em cada um dos casos, diferentes formas de cooperação envolvem empresas líderes, tanto de fora como nacionais, e fornecedores locais. Para entender melhor o desenvolvimento econômico que resulta dessa territorialidade das RPG de petróleo, seria necessário analisar a governança dessas redes: Os proprietários das refinarias mostradas nos mapas 1 e 2 cooperam com parceiros locais, por exemplo, para a manutenção e modernização das refinarias? Como é distribuído o lucro obtido com a venda dos produtos das refinarias? As refinarias estão relacionadas com qualquer atividade de pesquisa ou transferência de capacitações para as empresas locais?

\section{CONTROLE CORPORATIVO}

A dispersão global e a integração de atividades econômicas, obviamente, implicam custos de transação. As empresas transnacionais evitam custos de transação ao estabelecerem uma rede mundial de escritórios que se especializam em regiões específicas. A pesquisa sobre empresas transnacionais confirma que estas tendem a organizar suas operações em nível regional e não global (ENRIGHT, 2005; RUGMAN e VERBEKE, 2005). A sede regional está hierarquicamente situada entre a sede global da empresa e suas subsidiárias locais (LAUDIEN e FREILING, 2011). A autoridade da sede regional está aparentemente vinculada ao controle ou pelo menos ao gerenciamento dos projetos da respectiva empresa em uma determinada região. Apesar de o grau de autonomia das sedes regionais variar de uma empresa para outra, as sedes regionais sempre atuam na articulação entre as escalas regional e global, e mantêm estreitas ligações com todas as subsidiárias nas respectivas regiões e com a sede global.

Pesquisas sobre cidades globais também confirmam que algumas cidades são locais-chave para escritórios regionais de empresas transnacionais. Parnreiter (2010) ressalta que 63\% das maiores empresas do México e $79 \%$ das empresas estrangeiras que operam no país têm sede na Cidade do México. Sendo assim, a cidade interliga a economia mexicana globalmente. Parnreiter, Haferburg e Oßenbrügge (2013) mostram que a liberalização econômica na África do Sul e no México foi acompanhada de um boom imobiliário por causa das empresas transnacionais que abriram escritórios nesses locais.

No caso do Brasil, há uma clara concentração das sedes corporativas no Rio de Janeiro. Todas as 14 empresas que aparecem na base A Barrel Full (2016b) como operadoras de poços de petróleo brasileiros têm a sua sede para o Brasil localizada no Rio de Janeiro, próximas à Petrobras. Isso se justifica pelo fato de que a Petrobras é a companhia dominante no setor de petróleo e gás brasileiro. Um consultor privado que possui um profundo conhecimento das práticas da Petrobras declarou numa entrevista com os autores deste artigo que "todos os que trabalham com a Petrobras [em atividades upstream] precisam estar no Rio de Janeiro". Além disso, ele sublinhou o fato de que a Petrobras especifica em seus contratos com empresas estrangeiras que estas têm de abrir um escritório próximo da sua sede ${ }^{10}$.

Entrevistas realizadas na Namíbia e na África do Sul com empresas transnacionais envolvidas no setor de petróleo e gás sugerem que as hierarquias dentro dessas empresas distinguem-se do que a literatura explica. Um entrevistado

\footnotetext{
${ }^{10}$ Entrevista presencial realizada com um consultor de petróleo e gás, São Paulo, 7 Maio 2014.

Estudos Geográficos, Rio Claro, 17(1): 91-114, jan./jun. 2019 (ISSN 1678-698X)
} http://www.periodicos.rc.biblioteca.unesp.br/index.php/estgeo 
da Namíbia sublinhou que estar presente no país onde a exploração ou a extração ocorre é muito importante, não só para construir relações pessoais com autoridades públicas e potenciais empresas parceiras locais, mas também para "mostrar que há comprometimento com o país"11. Outro entrevistado, cujo escritório está localizado na Cidade do Cabo, ressaltou que a África do Sul - a economia emergente que possui todas as vantagens para hospedar uma cidade gateway no setor de petróleo e gás (SCHOLVIN, 2017) - ainda é um Estado fronteiriço nesse setor. Isto significa que os maiores atores do setor upstream primeiramente deslocaram-se para outros países da África Subsaariana. Mais tarde, abrem escritórios na Cidade do Cabo interessados nos recursos internos do país ${ }^{12}$.

Em outras palavras, no setor de petróleo e gás aparentemente, o controle corporativo é mais disperso geograficamente do que a literatura sobre empresas transnacionais sugere. Pode-se esperar que isso tenha um impacto positivo no desenvolvimento nos países ricos em petróleo e gás. Entretanto, em nível nacional, a concentração do controle corporativo nas cidades gateway dificulta 0 desenvolvimento de áreas periféricas. Como os contratos com os prestadores de serviços são negociados e assinados nas cidades gateway, as pequenas e médias empresas das cidades próximas aos locais onde ocorre a exploração de recursos enfrentam o desafio de se deslocarem para as cidades gateway ou abrir filiais nesses locais. Caso contrário, essas empresas dificilmente serão contratadas pelos operadores dos poços. "Gostaríamos de ver as decisões sendo tomadas aqui [mas] toda vez que estamos negociando um projeto, se não formos a Buenos Aires, não podemos finalizar o acordo", afirmam representantes de uma associação de empresas de petróleo e gás em Neuquén, Argentina ${ }^{13}$.

\section{PRESTAÇÃO DE SERVIÇOS}

A dimensão prestação de serviços das cidades gateway é a mais próxima do debate sobre as cidades globais, tal como moldado por Sassen (2001a, 2001b). Há crescente consenso na literatura sobre serviços avançados de que essas empresas precisam manter uma ampla rede de afiliadas locais para acessar mercados em todo o mundo (DANIELS, 2007; DICKEN, 2015). O estudo sobre a cidade de Hamburgo por Parnreiter (2015) aproxima RPG e cidades globais mostrando que os vários serviços requeridos para as RPG são específicos do lugar: "da pesquisa de mercado à comunicação pós-venda, [...], da abertura de uma conta bancária à administração de aposentadorias, [os serviços prestados às empresas transnacionais por empresas que se especializam na prestação de serviços avançados] são necessários para que seus clientes possam conduzir os seus negócios de forma eficiente" (2015, p. 07).

Essenciais como são, os serviços avançados estão integrados nas cidades globais, tornando-as gateways. Em seu estudo sobre a Cidade do México, Parnreiter conclui que "empresas de serviços [baseadas na Cidade do México] conectam-se com empresas de várias cadeias de produtos globais que se iniciam no México (como no caso do petróleo), ou desdobram-se para o país (como na indústria automotiva) ou terminam lá (por exemplo, os produtos vendidos no Wal-Mart)"

\footnotetext{
${ }^{11}$ Entrevista presencial realizada com o gerente nacional de uma empresa transnacional de petróleo e gás, Windhoek, 18 Agosto 2016.

${ }^{12}$ Entrevista presencial realizada com o executivo chefe de uma empresa transnacional de petróleo e gás, Cidade do Cabo, 11 Agosto 2016.

${ }^{13}$ Entrevista presencial realizada com diretores da câmara local de prestadores de serviços, Neuquén, 23 November 2017.

Estudos Geográficos, Rio Claro, 17(1): 91-114, jan./jun. 2019 (ISSN 1678-698X) http://www.periodicos.rc.biblioteca.unesp.br/index.php/estgeo
} 
(2010, p. 42). Parnreiter, além disso, aponta que, embora a Cidade do México seja crucial para a gestão de RPG, a cidade não se caracteriza como um centro de comando e controle. Como consequência, seu papel na governança de RPG permanece limitado.

Nesse sentido, o presente trabalho também sugere que as cidades gateway são centros de serviços, mas os serviços que elas fornecem não são necessariamente os serviços avançados comumente analisados em pesquisas sobre cidades globais. A Cidade do Cabo, por exemplo, é um relevante polo de serviços para o setor de petróleo e gás, cobrindo as atividades upstream em toda a África Subsaariana (SCHOLVIN, 2017). Adicionalmente, empresas dos ramos de serviços avançados, como Ernst \& Young e KPMG, por exemplo, têm escritórios na Cidade do Cabo. Um entrevistado de uma dessas empresas explicou que seu trabalho consiste em propor estratégias de negócios para clientes do exterior, o que exige conhecimento específico do lugar. Dado que as empresa entrevistadas têm escritórios em toda a África Subsaariana, o escritório na Cidade do Cabo raramente atua em negócios em outros países ${ }^{14}$.

O fato de a Cidade do Cabo concentrar vários prestadores de serviços que, na maioria dos casos, não estão disponíveis nos países subsaarianos que possuem recursos de petróleo e gás, torna a cidade um local atraente para empresas transnacionais. Elas encontram importantes intermediários lá e podem usar a Cidade do Cabo como um centro de reparos para plataformas de petróleo e navios. Além disso, os próprios prestadores de serviços beneficiam-se da densidade de empresas do setor. Um gerente de uma empresa de engenharia marítima internacional que está ativa em vários países da África Subsaariana salientou que estar na Cidade do Cabo permite que sua empresa se absteça de quase tudo localmente, ou seja, de parceiros confiáveis e com quase nenhum atraso. Quando se trabalha em outro lugar na África Subsaariana, o fornecimento vem frequentemente da Cidade do Cabo: "descobrimos que se não nos podemos abastecer no local, então nos abastecemos na Cidade do Cabo e os fornecedores enviam diretamente para onde precisarmos" 15.

A análise dos dados extraídos da base A Barrel Full (2016b) sugerem um status similar para o Rio de Janeiro, servindo de gateway para o Brasil. Embora incompletos, os dados mostram que, além da cidade do Rio de Janeiro, apenas São Paulo e as cidades de Aracruz (Espírito Santo) e Macaé e Niterói (Rio de Janeiro) aparecem como locais dos escritórios dos prestadores de serviços mais importantes. O Rio de Janeiro claramente domina, com 20 das 36 sedes das maiores prestadoras de serviços localizadas ali. Lugares periféricos, como o Guarujá, são importantes como locais de montagem de equipamentos para operações offshore. Essas atividades são, aparentemente, também desempenhadas na área portuária do Rio de Janeiro e nos distritos industriais próximos. Ainda assim, o diretor local de uma prestadora de serviços internacional declarou em uma entrevista com os autores que sua empresa encontrou um terreno suficientemente grande para seu estaleiro apenas no Guarujá, onde agora coopera com fornecedores de segundo e terceiro níveis de todo o Estado de São Paulo ${ }^{16}$.

\footnotetext{
${ }^{14}$ Entrevista presencial realizada com um gerente senior de um fornecedor de serviços avançados, Cidade do Cabo, 4 Agosto 2016.

${ }^{15}$ Entrevista presencial realizada com o diretor regional de uma empresa de engenharia marítima internacional, Cidade do Cabo, 10 Agosto 2016.

${ }^{16}$ Entrevista presencial realizada com o director local de um fornecedor de serviços upstream, Guarujá, 19 Abril 2017.

Estudos Geográficos, Rio Claro, 17(1): 91-114, jan./jun. $2019 \quad$ (ISSN 1678-698X) http://www.periodicos.rc.biblioteca.unesp.br/index.php/estgeo
} 


\section{GERAÇÃO DE CONHECIMENTO}

Por geração de conhecimento entende-se processos cooperativos que podem envolver empresas locais e não-locais que juntas buscam adaptar tecnologias existentes às particularidades locais ou comercializar globalmente 0 conhecimento desenvolvido no âmbito local. Tödtling, Lehner e Trippl (2006) apontam que, diferentemente de relações de mercado, spillovers - por exemplo, de institutos de pesquisa para o setor produtivo - são altamente localizados. Eles se diferenciam das relações de mercado porque raramente envolvem relações contratuais e compensações formais pelo conhecimento adquirido, apesar de eles serem impulsionados por instituições como parques tecnológicos. Diversos pesquisadores têm mostrado que locais urbanos são mais adequados para a geração de inovações e estabelecimento de relações inter-firma (FLORIDA, 2005; HOSPERS, 2003; YUSUF e NABESHIMA, 2005).

O setor brasileiro de petróleo e gás é um bom exemplo, nesse sentido, de formação de redes inovativas. A empresa-chave é a gigante semi-estatal Petrobras, líder mundial em tecnologia de exploração offshore ${ }^{17}$. A exploração e extração de petróleo em águas profundas e ultra-profundas requerem investimentos consideráveis em inovação tecnológica, em especial nos produtos e serviços ofertados pelos subcontratados. Atualmente, dois parques tecnológicos brasileiros são orientados, entre outros setores, a petróleo e gás. Um deles está em estágio inicial e localiza-se na cidade portuária de Santos. O outro, no qual este artigo se concentrará a seguir, encontra-se na cidade do Rio de Janeiro, na llha do Fundão.

A criação do parque no Rio de Janeiro remonta a 1963, quando o Instituto de Pós-Graduação e Pesquisa de Engenharia (COPPE) foi inaugurado na llha do Fundão pela Universidade Federal do Rio de Janeiro (UFRJ). Em 1997, o conselho da UFRJ aprovou a criação do parque tecnológico. Demorou mais seis anos até que o primeiro laboratório de pesquisa, o Tanque Oceânico, que explora tecnologias aplicadas no mar, iniciasse suas atividades. Outros laboratórios mantidos pela COPPE realizam pesquisas sobre tecnologias no setor de gás natural, desenvolvem metodologias para mecânica computacional, testam diversos produtos utilizados no setor de petróleo e gás e trabalham na recuperação de ecossistemas.

Diversas empresas foram incubadas nesse ambiente e várias empresas líderes globais do setor encontram-se lá instaladas. Algumas empresas importantes do parque são:

- Baker Hughes, cujo centro de pesquisa no parque concentra-se na caracterização de reservatórios e otimização de perfuração, conclusão e produção. Procura criar tecnologias aplicáveis em operações em águas profundas e pré-sal.

- Halliburton, que anunciou a abertura de um centro de pesquisa no parque tecnológico, com vistas ao desenvolvimento de software especializado na exploração e extração no nível pré-sal.

- Schlumberger, que dirige um laboratório no parque dedicado à solução dos desafios associados às operações de águas profundas e pré-sal.

- Ambidados, fundada por ex-alunos da COPPE, que fornece serviços de aquisição, processamento e análise de dados relevantes para operações offshore. $\mathrm{O}$

\footnotetext{
17 Em maio de 2015, a Petrobras recebeu pela terceira vez o "OTC Distinguished Achievement Award” para empresas, organizações e instituições. Isso confirma o notável desempenho da Petrobras em relação às tecnologias desenvolvidas para extração de petróleo e gás. O prêmio é concedido anualmente para a Offshore Technology Conference, que reúne praticamente todas as principais associações empresariais e empresas envolvidas no setor offshore de petróleo e gás.

Estudos Geográficos, Rio Claro, 17(1): 91-114, jan./jun. 2019 (ISSN 1678-698X) http://www.periodicos.rc.biblioteca.unesp.br/index.php/estgeo
} 
mais importante é um sistema para aquisição de dados em tempo real em qualquer lugar offshore.

- Oilfinder, outra empresa brasileira do parque, que desenvolveu tecnologia pioneira para identificar a localização precisa de petróleo no fundo do mar, utilizando apenas tecnologias de detecção remotas, evitando riscos ambientais e operacionais associados ao envio de navios a depósitos de petróleo em potencial.

Entrevistas realizadas pelos autores deste artigo revelam o esforço da Petrobras em transformar o parque tecnológico em um ambiente institucionalmente seguro para atrair empresas líderes internacionais e seus centros de pesquisa e desenvolvimento. Segundo esses relatos, a carência das empresas nacionais por conhecimento produtivo e tecnologias mais avançadas para explorar petróleo recém descoberto em águas ultra-profundas, traduziu-se em duplo efeito. Por um lado, a Petrobras teria intensificado suas atividades de pesquisa e desenvolvimento em seus institutos de pesquisa localizados nesse parque. E, por outro, ela teria convidado diretamente empresas líderes internacionais a instalarem-se nesse parque, o que de fato ocorreu ${ }^{18}$.

Em um efeito spill-over, outras empresas, como a FMC Technologies que já operava no Rio de Janeiro por muito anos, resolveram neste parque tecnológico também concentrar suas atividades em especial as relacionadas à pesquisa e desenvolvimento, tornando este ambiente em um pólo de atração de empresas globais $^{19}$. De acordo com Rocha e Urraca-Ruiz (2012), o parque tecnológico do Rio de Janeiro não serve apenas como um gateway ao Brasil e os seus recursos offshore. Baker Hughes e Schlumberger sugeriram em entrevistas que elas procuram aprender sobre as condições de exploração e produção do pré-sal, porque sabem que o conhecimento desenvolvido no Brasil pode ser usado em outros lugares. Empresas locais, como Oilfinder, vêm benefícios por estarem localizadas em uma gateway city, já que esta localização gera oportunidades de cooperação com a Petrobras e seus parceiros internacionais ${ }^{20}$.

\section{CONCLUSÃO}

O presente artigo avança no conceito de cidades gateway e do desenvolvimento no contexto de redes. As cidades gateway são marcadas por cinco dimensões, servindo como articuladoras em RPG. Contudo, nem toda cidade gateway cumpre todas as cinco dimensões. Cada uma delas pode surgir isoladamente, transformando uma cidade global em um gateway.

A dimensão gateway mais básica é o transporte e a logística. Neste artigo, esta dimensão é exemplificada por Buenos Aires e Durban. O papel gateway de Buenos Aires deriva do fato de a cidade sediar o maior porto da Argentina e de ser o ponto nodal do transporte aéreo e oferecer uma variedade de serviços a preços competitivos. Durban é essencial para o transporte terrestre e marítimo de produtos refinados na África do Sul e gerador de oportunidades para as empresas locais participarem nas RPG.

As cidades gateway são também locais-chave no processamento industrial. Dessa forma, elas geram ligações globais e regionais. No setor de petróleo e gás há

\footnotetext{
${ }^{18}$ Entrevista presencial realizada com a diretoria do Parque Tecnológico do Rio de Janeiro, Rio de Janeiro, 12 Dezembro 2016.

${ }^{19}$ Entrevista presencial realizada com a representante legal da FMC Technologies, Rio de Janeiro, 5 Junho 2017.

${ }^{20}$ Entrevista presencial realizada com a representante legal de Oilfinder, Rio de Janeiro, 5 Junho 2017.

Estudos Geográficos, Rio Claro, 17(1): 91-114, jan./jun. $2019 \quad$ (ISSN 1678-698X) http://www.periodicos.rc.biblioteca.unesp.br/index.php/estgeo
} 
uma concentração de refinarias próxima aos principais mercados: empresas transnacionais usam cidades como Durban e São Paulo para abastecer mercados próximos. No que diz respeito ao desenvolvimento econômico, questões de vínculos entre investidores não-locais e empresas locais, bem como a captura de valor são críticos.

O controle corporativo é uma das características tradicionalmente definidoras de cidades globais. Para atuar em várias partes do mundo, muitas empresas utilizam um número limitado de sedes regionais como intermediárias entre suas respectivas sedes globais e numerosas subsidiárias. As cidades que abrigam sedes regionais são marcadas por um ambiente de negócios relativamente favorável. No entanto, a presente pesquisa sugere que as empresas internacionais do setor de petróleo e gás parecem não organizar suas RPG a partir da sede regional, pelo menos não de forma evidente. Espera-se que isso permita 0 desenvolvimento nos países ricos em petróleo e gás, mas em escala nacional parece haver concentração em cidades como Buenos Aires, em detrimento de locais periféricos.

A prestação de serviços de bancos/finanças, contabilidade, direito e publicidade é outro critério definidor das cidades globais. A pesquisa de Parnreiter (2010, 2015) mostra que algumas cidades do mundo tornam-se portas de entrada para suas respectivas áreas de influência, oferecendo serviços avançados para empresas transnacionais. Aprende-se, portanto, com o setor de petróleo e gás que existem vários outros serviços que tornam algumas cidades gateways. A Cidade do Cabo é um gateway para a África Subsaariana por causa de empresas de engenharia que fornecem insumos críticos para transnacionais de petróleo e gás, que atuam na própria Cidade do Cabo ou que enviam funcionários e equipamentos à região. No Rio de Janeiro concentram-se fornecedores internacionais do setor upstream. Lugares como Guarujá parecem beneficiar-se dos efeitos de transbordamento: a falta de terrenos adequados para estaleiros no Rio de Janeiro contribui para que investidores estrangeiros procurem por localizações alternativas, próximas aos principais locais de extração de petróleo e gás.

A quinta dimensão gateway é a geração de conhecimento, ou seja, a adaptação do conhecimento externo às especificidades locais ou a preparação do conhecimento local para o mercado global. Nas cidades gateway encontramos redes informais de empreendedores inovadores que estão ligados a redes formais. Estes últimos reúnem institutos de pesquisa locais e grandes empresas transnacionais, geralmente do exterior. As cidades gateway, portanto, ligam diferentes esferas, como exemplifica o para o parque tecnológico especializado em petróleo e gás no Rio de Janeiro.

Estudos Geográficos, Rio Claro, 17(1): 91-114, jan./jun. $2019 \quad$ (ISSN 1678-698X) http://www.periodicos.rc.biblioteca.unesp.br/index.php/estgeo 
Cidades Gateway...

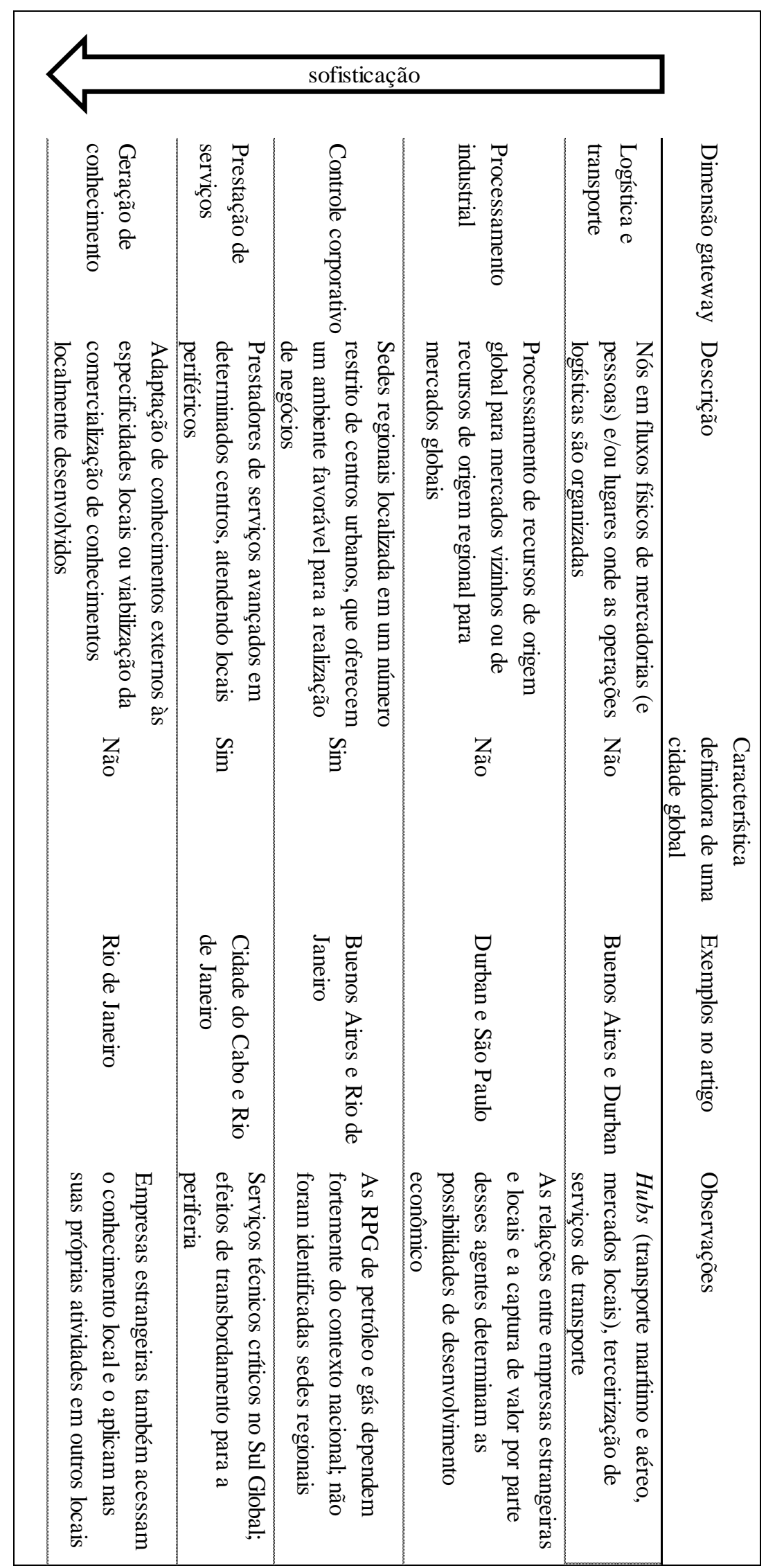

Quadro 1 - Dimensões gateway e exemplos

Fonte: elaboração própria.

Estudos Geográficos, Rio Claro, 17(1): 91-114, jan./jun. 2019 (ISSN 1678-698X) http://www.periodicos.rc.biblioteca.unesp.br/index.php/estgeo 
Embora este artigo seja principalmente uma revisão de literatura e de conceituação de cidades gateway e suas cinco dimensões, os exemplos empíricos fornecidos demonstram que conectar RPG e cidades globais gera importantes descobertas sobre os processos econômicos globais e regionais, incluindo 0 desenvolvimento em um contexto de redes. Além disso, os casos explorados no artigo evidenciaram que a conexão dos conceitos deve ir além de controle corporativo e serviços avançados que tradicionalmente formam o núcleo de pesquisa em cidades globais.

\section{REFERÊNCIAS}

A BARREL FULL. Global Refeneries. Disponível em: http://abarrelfull.wikidot.com/global-refineries. Acesso em: Aug. 1 2017, 2016a.

South American Oil And Gas Fields. Disponível em: http://abarrelfull.wikidot.com/south-american-oil-and-gas-fields. Acesso em Aug. 1, $2016 b$.

AGÊNCIA INTERNATIONAL DE ENERGIA. Statistics. Disponível em: https://www.iea.org/statistics/statisticssearch. Acesso em: Aug. 22 2017, 2016.

AKINBOADE, O. A.; LALTHAPERSAD-PILLAY, P. The NEPAD Initiative and the Prospects of Business Opportunities in the Rest of Africa for South African Firms Based in Gauteng. Development Southern Africa, v. 26, n. 01, p. 131-155, 2009.

ALDERSON, A. S.; BECKFIELD, J. Power and Position in the World City System. American Journal of Sociology, v. 109, n. 04, p. 811-851, 2004.

ALDERSON, A. S.; BECKFIELD, J. Corporate Networks of World Cities. In: DERUDDER, B.; HOYLER, M.; WITLOX, F. (Org.). International Handbook of Globalization and World Cities. Cheltenham: Edward Elgar. p. 126-134, 2012.

BOWEN, J. T.; LEINBACH, T. R. Global Production Networks and Competitive Advantage: Air Freight Services and the Electronics Industry in Southeast Asia. Economic Geography, v. 82, n. 02, p. 147-166, 2006.

BRIDGE, G.; LE BILLON, P. Oil. Malden: Polity Press, 2013.

BURGHARDT, A. F. A Hypothesis about Gateway Cities. Annals of the Association of American Geographers, v. 61, n. 02, p. 269-285, 1971.

COE, N. M.; HESS, M.; YEUNG, H. W.; DICKEN, P.; HENDERSON, J. 'Globalising' Regional Development: A Global Production Networks Perspective. Transactions of the Institute of British Geographers, v. 29, n. 04, p. 468-484, 2004.

COE, N. M.; DICKEN, P.; HESS, M. Global Production Networks: Realizing the Potential. Journal of Economic Geography, v. 08, n. 03, p. 271-295, 2008. 
COE, N. M.; YEUNG, H. W. Global Production Networks: Theorizing Economic Development in an Interconnected World. Oxford: Oxford University Press, 2015.

DANIELS, P. W. A Global Service Economy?. In: BRYSON, J. R.; DANIELS, P. W. (Org.). The Handbook of Service Industries. Cheltenham: Edward Elgar. p. 103$125,2007$.

DICKEN, P. Global Shift: Mapping the Changing Contours of the World Economy. London: Sage, 2015.

DRAPER, P.; SCHOLVIN, S. The Economic Gateway to Africa?: Geography, Strategy and South Africa's Regional Economic Relations. SAllA Occasional Paper $121,2012$.

ENRIGHT, M. J. Regional Management Centers in the Asia-Pacific. Management International Review, v. 45, n. 01, p. 59-82, 2005.

FLORIDA, R. L. Cities and the Creative Class, London: Routledge, 2005.

FRIEDMANN, J. The World City Hypothesis. Development and Change, v. 17, n. 01, p. 69-83, 1986.

FRIEDMANN, J.; WOLFF, G. World City Formation: An Agenda for Research and Action. International Journal of Urban and Regional Research, v. 06, n. 03, p. 309-344, 1982.

GRANT, R.; NIJMAN. J. Globalization and the Corporate Geography of Cities in the Less-Developed World. Annals of the Association of American Geographers, v. 92, n. 02, p. 320-340, 2002.

GRUBESIC, T. H.; MATISZIW, T. C. World Cities and Airline Networks. In: DERUDDER, B.; HOYLER, M.; WITLOX, F. (Org.). International Handbook of Globalization and World Cities. Cheltenham: Edward Elgar. p. 97-116, 2012.

HENDERSON, J.; DICKEN, P.; HESS, M.; COE, N.; YEUNG, H. W. Global Production Networks and the Analysis of Economic Development. Review of International Political Economy, v. 09, n. 03, p. 436-464, 2002.

HESSE, M. Cities, Material Flows and the Geography of Spatial Interaction: Urban Places in the System of Chains. In: DERUDDER, B.; WITLOX, F. (Org.). Commodity Chains and World Cities. Oxford: Wiley-Blackwell. p. 91-110, 2010.

HOSPERS, G. J. Creative Cities: Breeding Places in the Knowledge Economy. Knowledge, Technology \& Policy, v. 16, n. 03, p. 143-162, 2003.

HUMPHREY, J. Globalization and Supply Chain Networks: The Auto Industry in Brazil and India. Global Networks, v. 03, n. 02, p. 121-141, 2003.

JACOBS, W.; DUCRUET, C.; DE LANGEN, P. Integrating World Cities into Production Networks: The Case of Port Cities. In: DERUDDER, B.; WITLOX, F.

Estudos Geográficos, Rio Claro, 17(1): 91-114, jan./jun. 2019 (ISSN 1678-698X) http://www.periodicos.rc.biblioteca.unesp.br/index.php/estgeo 
(Org.). Commodity Chains and World Cities. Oxford: Wiley-Blackwell. p. 111-135, 2010.

KNOX, P. L. Globalization and Urban Economic Change. Annals of the American Academy of Political and Social Science, n. 551, p. 17-27, 1997.

LAUDIEN, S. M.; FREILING, J. Direktinvestive internationale Unternehmenstätigkeit und das GLOCAL-Dilemma: Die koordinative Rolle von Regional Headquarters. Zeitschrift für Management, v. 06, n. 04, p. 351-372, 2011.

PARNREITER, C. Global Cities in Global Commodity Chains: Exploring the Role of Mexico City in the Geography of Global Economic Governance. In: DERUDDER, B.; WITLOX, F. (Org.). Commodity Chains and World Cities. Oxford: Wiley-Blackwell. p. 43-64, 2010.

PARNREITER, C. Managing and Governing Commodity Chains: The Role of Producer Service Firms in the Secondary Global City of Hamburg. Die Erde, v. 46, n. 01, p. 01-15, 2015.

PARNREITER, C.; HAFERBURG, C.; OßENBRÜGGE, J. Shifting Corporate Geographies in Global Cities of the South: Mexico City and Johannesburg as Case Studies. Die Erde, v. 144, n. 01, p. 01-16, 2013.

RABACH, E.; KIM, E. M. Where is the Chain in Commodity Chains?: The Service Sector Nexus. In: GEREFFI, G.; KORZENIEWICZ, M. (Org.). Commodity Chains and Global Capitalism. London: Praeger. p. 123-143, 1994.

RAMOS SCHIFFER, S. São Paulo: Articulating a Cross-Border Region. In: SASSEN, S. (Org.). Global Networks: Linked Cities. London: Routledge. p. 209-236, 2012.

ROBINSON, R. Ports as Elements in Value-Driven Chain Systems: The New Paradigm. Maritime Policy and Management, v. 29, n. 03, p. 241-255, 2002.

ROCHA, F.; RUIZ, A. U. The Role of the Network Coordinator in the Attraction of Foreign Investment in R\&D: The Case of the Brazilian Oil and Gas Industry. Transnational Corporations, v. 20, n. 03, p. 33-60, 2012.

ROSSI, E. C.; BEAVERSTOCK, J. V.; TAYLOR, P. J. Transaction Links through Cities: "Decision Cities" and "Service Cities". Geoforum, v. 38, p. 628-642, 2007.

ROSSI, E. C.; TAYLOR, P. J. Banking Networks across Brazilian Cities: Interlocking Cities Within and Beyond Brazil. Cities, v. 22, n. 05, p. 381-393, 2005.

RUGMAN, A. M.; VERBEKE, A. Towards a Theory of Regional Multinationals: A Transaction Cost Economics Approach. Management International Review, v. 45, n. 01, p. 05-17, 2005.

SASSEN, S. The Global City. Princeton: Princeton University Press, 2001a.

Estudos Geográficos, Rio Claro, 17(1): 91-114, jan./jun. $2019 \quad$ (ISSN 1678-698X) http://www.periodicos.rc.biblioteca.unesp.br/index.php/estgeo 
SASSEN, S. Cities in the Global Economy. In: PADDISON, R. (Org.). Handbook of Urban Studies. London: Sage. p. 256-272, 2001b.

SCHOLVIN, S. Cape Town as a Gateway City: Interlinking the Sub-Saharan Oil and Gas Sector Globally. In: HARTZENBERG, T.; ERASMUS, G. (Org.). Monitoring Regional Integration in Southern Africa 2015/2016. Stellenbosch: TRALAC. p.128-181, 2017.

SHORT, J. R.; BREITBACH, C.; BUCKMAN, S.; ESSEX, J. From World Cities to Gateway Cities: Extending the Boundaries of Globalization Theory. City, v. 04, n. 03, p. 317-340, 2000.

SIGLER, T. J. Relational Cities: Doha, Panama City, and Dubai as 21st Century Entrepôts. Urban Geography, v. 34, n. 05, p. 612-633, 2013.

SMITH, R. G. Beyond the Global City Concept and the Myth of "Command and Control". International Journal of Urban and Regional Research, v. 38, n. 01, p. 98-115, 2014.

SURBORG, B. World Cities Are just "Basing Points for Capital": Interacting with the World City from the Global South. Urban Forum, v. 22, n. 04, p. 315-330, 2011.

TAYLOR, P. J.; WALKER, D. R.; CATALANO, G.; HOYLER, M. Diversity and Power in the World City Network. Cities, v. 19, n. 04, p. 231-241, 2002.

TÖDTLING, F.; LEHNER, P.; TRIPPL, M. Innovation in Knowledge Intensive Industries: The Nature and Geography of Knowledge Links. European Planning Studies, v. 14, n. 08, p. 1035-1058, 2006.

TRIBE, M. An Overview of Manufacturing Development in Sub-Saharan Africa. In: BELSHAW, D; LIVINGSTONE, I. (Org.). Renewing Development in Sub-Saharan Africa: Policy, Performance and Prospects. London: Routledge. p. 263-284, 2002.

WALL, R. S.; VAN DER KNAAP, B. Centrality, Hierarchy and Heterarchy of Worldwide Corporate Networks. In: DERUDDER, B.; HOYLER, M.; WITLOX, F. (Org.). International Handbook of Globalization and World Cities. Cheltenham: Edward Elgar. p. 209-229, 2012.

WANG, J. J.; CHENG, M. C. From a Hub Port City to a Global Supply Chain Management Center: A Case Study of Hong Kong. Journal of Transport Geography, v. 18, n. 01, p. 104-115, 2010.

World Bank (2009). World Development Report: Reshaping Economic Geography. Disponível em: https://openknowledge.worldbank.org/handle/10986/5991. Acesso em Aug. 17 2017, 2009.

YUSUF, S.; NABESHIMA, K. Creative Industries in East Asia. Cities, v. 22, n. 02, p. 109-122, 2005.

Estudos Geográficos, Rio Claro, 17(1): 91-114, jan./jun. $2019 \quad$ (ISSN 1678-698X) http://www.periodicos.rc.biblioteca.unesp.br/index.php/estgeo 
Cidades Gateway...

\section{Agradecimentos}

Este artigo foi apresentado em um workshop na Universidade Estadual de Campinas em fevereiro de 2016. Agradecemos os comentários de Paula Bastos, Javier Revilla Diez e Maurício Serra. O workshop lançou o projeto "Gateway Cities and their Hinterland", financiado pela Sociedade Alemã de Amparo à Pesquisa (Deutsche Forschungsgemeinschaft, DFG) e pela Fundação de Amparo à Pesquisa do Estado de São Paulo (FAPESP).

Estudos Geográficos, Rio Claro, 17(1): 91-114, jan./jun. $2019 \quad$ (ISSN 1678-698X) 